\title{
Pembuatan Identitas Perusahaan Pembuat Kontainer Kafe Vessels
}

\author{
Dessyca Elizabeth \\ STIKOM The London School of Public Relations - Jakarta
}

\begin{abstract}
ABSTRAK
Vessels merupakan perusahaan jasa modifikasi pembuatan kontainer kafe sekaligus menyediakan training terhadap sumber daya manusia perancangan kontainer kafe. Perusahaan Vessels masih tergolong baru, berdiri sejak 2018, dan belum memiliki identitas perusahaan seperti logo. Untuk itu dirancang identitas perusahaan yang juga meliputi pengaplikasian logo pada stationary set, business documents, uniform, vehicle dan company profile. Perancangan yang telah menghasilkan identitas perusahaan tersebut disambut baik oleh pemilik Vessels. Pemilik merasa nyaman dan percaya diri dengan adanya visualisasi identitas perusahaan. Pemilik Vessels memilih tiga sketsa yang dibuat perancang karya. Logo yang dipilih merupakan logo yang merepresentasikan dirinya dan perusahaan Vessels.
\end{abstract}

Kata kunci: identitas perusahaan; identitas visual; logo, profil perusahaan; perancangan

\section{Creating Corporate Identity for Vesels Container Café Maker}

\begin{abstract}
Vessels is modification service provider, specializes in making container cafe and training the human resources. Vessels is still a young ans green company, since it was established in 2018. In relation to its infancy status, thus Vessels has yet to have a corporate identity such as logo. Corporate Identity preparation and planning also covers the application of the company's logo and identity into the relevant visual media such as stationary sets, business documents, uniforms, vehicles and company profiles. The company made it through the steps from Alina Wheeler.
\end{abstract}

Keywords: corporate identity; visual identity; logo; company profile; design

\section{PENDAHULUAN}

Semua yang dibangun dan menjadi kuat, berasal dari adanya identitas diri sendiri maupun organisasi, khususnya perusahaan. Perusahaan yang mempunyai identitas dapat merepresentasikan image dari perusahaan tersebut. Menurut Nielsen, sebanyak 66 persen konsumer global yang memiliki akses internet lebih memilih membeli produk baru dari brand yang telah dikenal dibandingkan beralih ke brand baru" (Nielsen.com, 2013). 
Identitas merupakan jati diri yang akan membentuk differensiasi atau memiliki ciri khas. Identitas berfungsi sebagai pembeda (Kotler \& Pfoertsch, 2008). Identitas adalah dasar atau inti dari terciptanya perusahaan tersebut. Perusahaan yang tidak memilki identitas akan sulit untuk bersaing.

Salah satu usaha yang banyak digemari masyarakat saat ini adalah bisnis kafe. Terbukti dari perkembangan berbagai industri bisnis, sektor food and beverages secara khusus menjadi salah satu yang paling pesat pertumbuhannya dengan angka keuntungan yang signifikan (Idris, 2017). Bisnis kafe yang semakin kompetitif di era digital ini juga memacu kreatifitas yang terus bermunculan -dengan konsep yang menarik, nyaman, serta branding yang kuat.

Dari segala macam jenis kafe, ada salah satu cara untuk membuat kafe tersebut menjadi besar secara cepat dan efektif yaitu dengan franchise. Di Indonesia, aktivitas franchise saat ini banyak dilakukan dan merupakan suatu fenomena bisnis yang baru (Solopos, 2016). Hal ini mulai banyak diminati karena kemudahan dalam persyaratan dan kategori usaha yang mudah diterima oleh masyarakat.

Untuk menentukan sebuah corporate identity yang tepat tidaklah mudah dan menjadi salah satu permasalahan yang tidak terstruktur. Banyak kriteria yang bersifat personal dari perusahaan sehingga tidak bisa menghasilkan corporate identity dengan segera. Sebagai suatu ekspresi visual, identitas perusahaan dapat diciptakan dan dijadikan tolak ukur terhadap nasib perusahaan tersebut.

Perusahaan kecil, menengah, hingga besar memerlukan perancangan logo dan corporate identity. Simbol atau logo merupakan aspek komunikasi antarperusahaan dan masyarakat (Setyoning, 2016). Simbol dalam berkomunikasi sudah ada sejak zaman awal peradaban manusia. Simbol banyak digunakan untuk tujuan berkomunikasi. Dalam buku Designing Brand Identity disebutkan "Symbols are vessels for meaning" (Wheeler, 2009).

Simbol merupakan wadah perusahaan, berisikan makna yang ingin disampaikan pada sasarannya. Simbol juga melibatkan kecerdasan, imajinasi, emosi, dengan cara yang tidak dilakukan oleh pembelajaran lain (Wheeler, 2009). Oleh karena itu, corporate identity harus mempunyai visi yang sama dengan rencana perusahaan.

Pada lima tahun belakangan ini harga properti, baik bangunan maupun lahan meningkat pesat di kota-kota besar seperti di Jakarta. Oleh karena itu, para calon wirausaha muda dan perintis bisnis baru, cenderung memilih alternatif yang lebih murah untuk memulai bisnisnya. Para startup melihat medium kontainer sebagai sebuah peluang bisnis, salah satunya dalam bentuk kafe kontainer. 
Salah satu penyedia jasa yang menyediakan kontainer kafe adalah Vessels, sebuah perusahaan yang bergerak dalam pembuatan container kafe untuk didistribusikan kepada pembisnis baru. Tahun 2017, Vessels meluncurkan ide untuk menjadi penyedia jasa kafe kontainer. Saat itu sudah ada yang menggunakan jasanya yaitu kafe Beyond Ropangnoodle di Bekasi. Pendiri Vessels melihat tren bisnis kafe menggunakan kontainer marak di luar negeri sehingga menerapkannya di Jakarta. Hal itu ditandai dengan banyaknya pembisnis baru, khususnya anak muda mempunyai keinginan membuka bisnis yang unik namun bermodal rendah.

Sasaran dari bisnis Vessels adalah pebisnis baru dan franchisee. Untuk memperkenalkan usaha ini kepada masyarakat, Vessels membutuhkan sebuah corporate identity yang merepresentasikan dari ciri khas dari perusahaan tersebut. Dalam konteks seperti itulah pengabdian kepada masyarakat ini dilaksanakan.

Menurut Bernstein perusahaan harus memperhatikan citra, karena perusahaan membutuhkan keterterimaan di khalayak konsumen sehingga persepsi citra harus selaras dengan citra diri perusahaan (Jabbar, 2014). Membangun citra diri, visual atau grafis diperlukan agar perusahaan dikenal masyarakat. Identitas visual pada sebuah perusahaan adalah wujud dasar dari sebuah komitmen perusahaan yang membentuk produk, lingkungan dan komunikasi.

Ada lima komponen dasar dari sistem identitas visual perusahaan (Jabbar, 2014) yaitu:

(1) Nama. Penamaan suatu brand dapat dinilai dari pemaknaan nama tersebut dan positioning goals dari suatu perusahaan. Kecintaan terhadap nama dapat didasarkan dari makna dan asosiasi yang dibangun seiring berjalannya waktu (Wheeler, 2009);

(2) Logotype, merupakan logo yang mempunyai ciri khas, bersifat tahan lama dan berkelanjutan. Bentuk dari logo yang baik dapat dimanipulasi untuk merepresentasikan kepribadian perusahaan (Wheeler, 2009);

(3) Tipografi, merupakan salah satu elemen yang dapat mempertahankan identitas yang efektif. Tipografi juga dapat mendukung strategi dari positioning perusahaan dan bersifat berkelanjutan (Wheeler, 2009);

(4) Warna, merupakan hal yang sudah terbukti dapat mempengaruhi psikologi manusia. Warna dalam pembentukan visual identity digunakan untuk membangkitkan emosi dan mengekspresikan karakter dari perusahaan. Hal ini dapat menjadi roda percepatan terhadap diferensiasi merek (Wheeler, 2009); 
(5) Tagline, tumbuh dari proses strategi dan kekreatifitas akan pembentukkan identitas perusahaan. Tagline adalah mantra atau kalimat perusahaan secara singkat yang dapat membantu menciptakan minat (Wheeler, 2009).

Perusahaan membutuhkan identitas. Salah satu fitur yang menentukan dari konsep identitas adalah menghindari upaya pengukuran apapun. Meski konsepnya sulit diukur, namun konsepnya masih ada sebagai fenomena dengan caranya sendiri dan identitas adalah salah satu konsep yang hanya memiliki definisi kerja, yang berfungsi untuk mengarahkan dan memberikan arahan penyelidikan (Bloch, 2013). Pernyataan ini menjelaskan identitas perusahaan terbentuk karena perilaku, komunikasi dan ymbol yang dinamai dengan Corporate Identity Mix (Diagram 1).

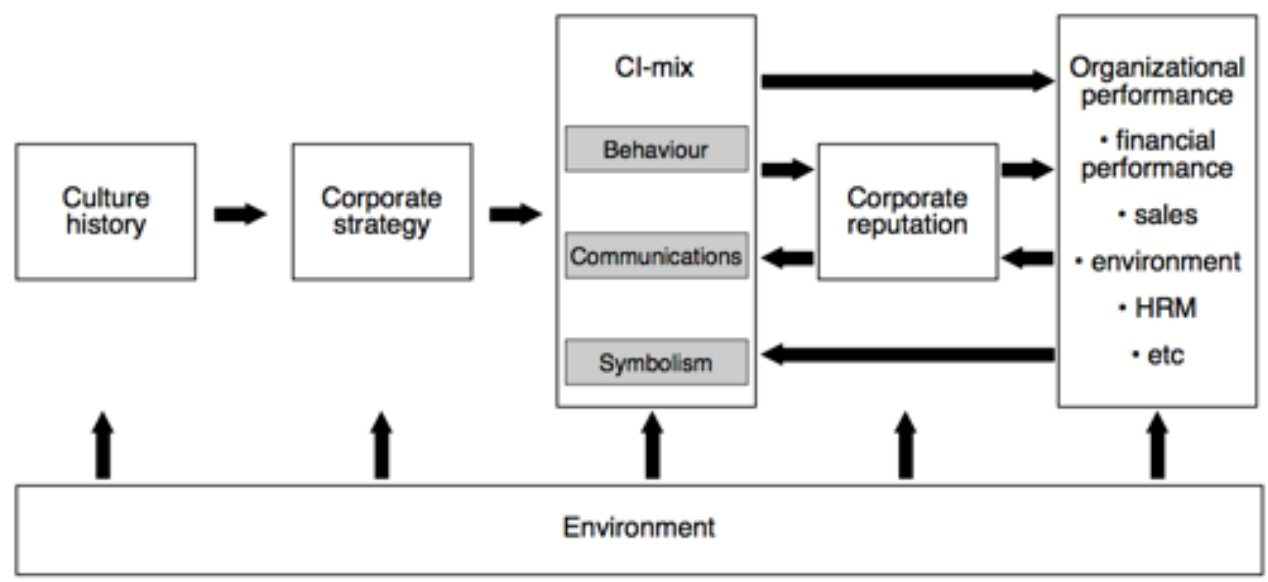

Source: van Reil Balmer (nd)

Diagram 1. Pembentukkan corporate identity mix (Balmer, 1997)

Pola Perilaku (Behaviour) berorientasi pada pembelajaran perilaku, berguna untuk pengembangan kompetensi dan untuk menunjukkan kemampuan teknis atau psikomotorik (Rostami, 2010);

Simbol, menurut Birkigt dan Stadler mengacu kepada seperangkat identitas visual yang diterapkan oleh organisasi bisnis baik di tingkat perusahaan maupun produk untuk menunjukkan kepemilikan dan mencapai diferensiasi" (Otubanjo, 2013).

Business to business (B2B) adalah model bisnis yang berfokus pada penjualan produk dan layanan antarperusahaan. Berbeda dengan model business to consumer (B2C) yang berhubungan dengan pelanggan langsung, B2B berhubungan langsung dengan antarperusahaan yang menawarkan bahan baku atau layanan yang dibutuhkan perusahaan untuk meningkatkan keuntungan, dari industri manufaktur hingga ritel. Business to business bergantung pada fungsi penjualan dan tim manajemen accounting untuk membangun dan memperkuat hubungan pelanggan (Uzialko, 2017). 


\section{METODE PELAKSANAAN}

Pengabdian kepada Masyarakat ini menggunakan metode diskusi atas sketsa yang ditampilkan setelah menerima berbagai masukan dari pemilik perusahaan. Terdapat tiga sketsa yang diajukan dan ketiganya dibahas secara mendalam dengan mengedepankan berbagai teori yang mendukungnya.

\section{HASIL DAN PEMBAHASAN}

Perancangan identitas dan profil perusahaan Vessels dibuat agar perusahaan Vessels mempunyai identitas yang kuat dan dapat memperlihatkan karakter dari perusahaan. Selain itu dengan adanya identitas, Vessels dapat mengidentifikasi segmentasi, melakukan pemasaran dan menjalankan bisnisnya secara mudah, tepat dan benar. Ada beberapa hal yang dapat menjadi masukan bagi perusahaan Vessels yaitu:

(1) Perusahaan Vessels dapat menggunakan stationary baru untuk media promosi diluar dari stationary yang sudah ada. Di luar dari stationary, Vessels dapat menggunakan media promosi yang lain seperti word of mouth atau event;

(2) Perusahaan Vessels dapat lebih aktif di bagian promosi dalam sosial media seperti Instagram atau Facebook. Perusahaan Vessels harus memiliki fitur chat yang mudah diakses oleh masyarakat seperti Whatsapp atau Line @. Selain fitur chat atau fitur teks, Vessels harus membuat konten video di youtube yang menampilkan identitas Vessels dan memberi informasi akan profil perusahaan serta portofolio pada perusahaan Vessels.

Sementara itu, tahapan pembuatan identitas perusahaan telah melalui Langkah-langkah sebagai berikut:

(1) Conducting Research, untuj membentuk keputusan yang tepat bagi perusahaan. Riset yang salah arah dapat menghalangi inovasi dalam perusahaan. Riset pasar yang dilakukan adalah pengumpulan, evaluasi, dan interpretasi data yang mempengaruhi keputusan pelanggan terhadap produk, layanan,dan merek;

(2) Clarifying Strategy, melakukan strategi untuk keberhasilan dalam perancangan identitas perusahaan seperti menentukan fokus, penamaan brand dan menentukan arah brand tersebut berjalan;

(3) Designing Identity. Logo, warna, typography dan pengaplikasian design pada brand diuji coba dan dinilai berdasarkan estetika dan tujuan perusahaan; 
(4) Creating Touchpoints. Pengaplikasian design juga berlaku dalam pengaplikasian pada sebuah atribut brand dan ditentukan atribut yang tepat agar perusahaan dapat berjalan dengan professional dan efesien. Atribut yang sudah ditentukan untuk brand Vessels meliputi kop surat, kartu nama, seragam karyawan, balpoin, USB, surat jalan, invoice, dan amplop;

(5) Managing Assets, melakukan peluncuran brand terhadap target. Peluncuran brand merupakan peluang yang baik untuk pemasaran. Organisasi harus cerdas dalam membangun kesadaran merek. Organisasi yang masih kecil mungkin belum mempunyai anggaran untuk mengadakan kampanye besar-besaran, namun bisa melalui brosur atau media online yang dikirimkan ke pelanggan, karyawan dan investor.

Adapun hasil sketsa yang kemudian diterima menjadi loga perusahaan, termasuk untuk digunakan di mobil dana stationary kits dapat dilihat selengkapnya pada Gambar 1, 2 dan 3.
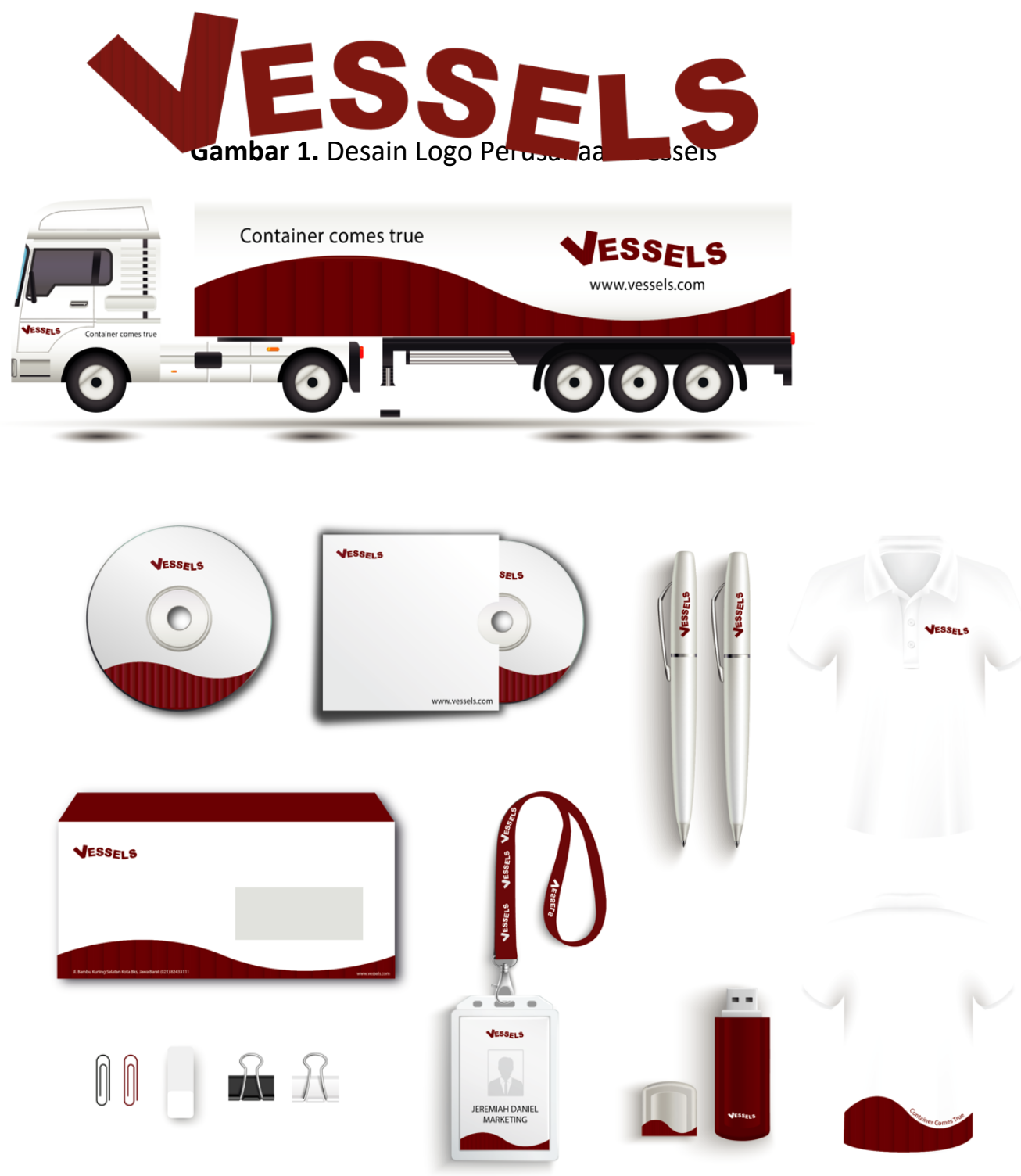


\section{SIMPULAN}

Setelah pembuatan identitas perusahaan, pemilik Vessels merasa puas atas karya ini. Hasil karya ini segera dipakai secara nyata untuk bisnis Vessels. Pemilik Vessels merasa nyaman dan percaya diri dengan adanya visualisasi akan identitas dari perusahaan Vessels ini. Mengenai logo, pemilik Vessels memilih ketiga sketsa yang dibuat perancang karya. Logo yang dipilih pemilik Vessels merupakan logo yang merepresentasikan dirinya dan perusahaan Vessels. Hal ini merupakan salah satu bentuk adanya kepemilikan seseorang pada suatu brand.

\section{DAFTAR PUSTAKA}

Balmer, J. M. (1997). Corporate Identity: The Concept, Its Measurement and Management, 31, 342. European Journal of Marketing, 31: 342.

Bloch, O. (2013). Corporate Identity and Crisis Response Strategies. Frankfurt: Springer VS.

Hadi, A. (2018). Delapan Unsur Seni Rupa. Diperoleh dari website: http://www.softilmu.com/2015/11/8-macam-unsur-unsur-seni-rupa-adalah.html

Idris, M. (2017). Modal Rp 1,3 Juta, Pemuda Ini Bisnis Kafe Susu Beromzet Ratusan Juta. Diperoleh dari website: https://finance.detik.com/solusiukm/3451051/modal-rp-13juta-pemuda-ini-bisnis-kafe-susu-beromzet-ratusan-juta

Jabbar, Z. (2014). The Impact of Corporate Visual Identity on Brand Personality. Brunei Business School, $10 . \quad$ Diperoleh dari E-journal: http://bura.brunel.ac.uk/bitstream/2438/8734/1/FulltextThesis.pdf

Nielsen.com. (2013, 01 22). Global Consumers More Likely to Buy New Products From Familiar Brands. Diperoleh dari website: http://www.nielsen.com/us/en/pressroom/2013/global-consumers-more-likely-to-buy-new-products-from-familiar-b0.html Otubanjo, O. (2013). The Extended Corporate Identity Mix. International Journal of Marketing Studies, $60 . \quad$ Diperoleh dari E-journal: www.ccsenet.org/journal/index.php/ijms/article/viewFile/23932/15169

Psychology, C. (2018). Maroon Color. Diperoleh dari website: The Psychology of Colors and the meanings: https://www.colorpsychology.org/maroon/

Rostami, K. (2010). The Implications of Behaviorism and Humanism theories in medical education. Research Institute for Gastroenterology and Liver Diseases, 1. Birmingham: University of Birmingham

Solopos, A. (2016, Mei 17). Bisnis Waralaba Tumbuh Pesat di Indonesia. Diperoleh dari website: https://economy.okezone.com/read/2016/05/17/320/1390833/bisniswaralaba-tumbuh-pesat-di-indonesia

Wheeler, A. (2009). Designing Brand Identity. New Jersey: John Wiley \& Sons, Inc. 